\title{
EDITORIAL
}

\section{Forty years of neuroendocrinology: a tribute to SM McCann}

On 13 June 1995 a symposium entitled 'Forty years of neuroendocrinology: a tribute to Samuel $M$. (Don) McCann' took place at the Masur auditorium, National Institutes of Health, as an official satellite of the Annual Meeting of the Endocrine Society, under the sponsorship of the National Institute of Mental Health (NIMH) and the National Institute of Child Health and Human Devel opment (NICHD). The presentations comprised a broad panel that reflected the scientific accomplishments of Don McCann over these last 40 years. As one listened to the presentations at this symposium as well as at the Endocrine Society Meeting, and looked at the audience, two things became very apparent. The first was the strength and vigor of McCann's research, which over 45 years evolved into a coherent body of knowledge that integrates various key concepts of biology into testable hypotheses, generating work that is conceptually novel and of profound physiological and medical relevance. As biomedical science moves into reductionism and specific systems are studied in great detail, it is very important to conceptually integrate networks of molecules into circuitries, systems, and functions in the intact organism. Don McCann has been able to examine relevant systems rigorously, keeping his work rel evant to function. The other point that was indisputable during the meeting was that in the process of expanding the frontiers of existing knowledge in neuroendocrinology, with a body of work that has included over 650 original manuscripts, the editing of two journals, Neuroendocrinology and Neuroimmunomodulation, and membership in the National Academy of Sciences, and in the American Academy of Arts and Sciences, Don trained several generations of investigators in the field. Those he trained have leading positions in academic medicine and are now deans of medical schools, chairpersons of productive academic departments, and internationally renowned investigators.

The specific scientific accomplishments of McCann and co-workers have been focused on the hypothalamic control of pituitary and vegetative functions. Forty-five years ago in 1952, McCann and colleagues discovered that epinephrine given intravenously would elevate blood adrenocorticotropin hormone (ACTH) levels. That represented the first of a series of seminal discoveries that

Correspondence: J Licinio, MD, Unit on Clinical Research, Clinical Neuroendocrinology Branch, Intramural Research Program, National Institute of Mental Health, NIH, BIdg 10, Rm 2D46, Bethesda, MD 20892-1284, USA. E-mail: licinio@nih.gov

Received 4 August 1997; revised and accepted 5 August 1997 are listed in Table 1. McCann's career has been compared to a trail of peptides: when he began his research studies there were only two brain peptides, oxytocin and vasopressin. Now, thanks in great part to Don's work, there are dozens of brain peptides identified, affecting most functions of the brain. When one looks at this field before Don started his work, and contrasts it to where it is today, it becomes very evident that Don's pioneering spirit has been a guiding force in neuroendocrinology in the last 45 years. We never had the privilege of working directly with Don, but we have collaborated long-distance over the last several years. We cannot cease to be truly impressed by Don's sharp intelligence, profound fund of knowledge, and tremendous ability to rapidly integrate apparently disparate concepts into a coherent framework leading to research that elucidates both function as well as key points in biology. We have asked ourselves what attributes can one person have to maintain such a productive and inspiring career over the past 45 years. Our conclusion is that the most important attributes to Don's success are actually very simple and include a genuine interest in people as individuals and not simply as executors of his projects: Don has mentioned to us that as he trained investigators he would assign newly discovered peptides to new fellows in his lab. Such mentoring is the reflection of true generosity that has given countless scientists unique opportunities as they were starting their careers. Finally, we would say that as one talks to Don it becomes very clear that neuroendocrinol ogy is for him not only a field of study or a discipline he helped launch. It is above all a key element of life. Life depends on vegetativefunctions: feeding, reproduction, sleep, cardi ovascular activity, water and el ectrolyte bal ance. Don's genuine enthusiasm and unquenchable curiosity and interest in life have fueled his career - and our fied for the last 45 years. In this issue of Mol ecular Psychiatry five papers, by Antunes-Rodrigues and McCann (pages 359-367), Martini (pages 373-376), Ojeda (pages 355358), Rettori and McCann (pages 350-354), and Webster et al (pages 368-372), provide a small sample of the bre adth of the research that was initiated or inspired by the work of SM McCann, and that was presented at the NIH on 13 June 1995.
J Licinio ${ }^{1}$, PW Gold ${ }^{1}$, GP Chrousos ${ }^{2}$ and EM Sternberg ${ }^{1}$
${ }^{1} \mathrm{Clinical}$ Neuroendocrinology Branch National Institute of Mental Heal th NIH, Bethesda, MD 20892-1284, USA
2Pediatric Endocrinology Section Developmental Endocrinology Branch NICHD, NIH, Bethesda, MD 20892-1862, USA 
Table 1 Summary of research accomplishments by McCann and co-workers

1 Discovery that epinephrine given intravenously would elevate blood ACTH (1952).

2 Delineation of the median eminence as the important site for hypothalamic control of gonadotropins and ACTH in rat and cat (1953-54).

3 Discovery that these lesions led to hypertrophy of the pars intermedia, suggesting that this was under inhibitory hypothalamic control (1953).

4 First evidence for the role of the arcuate nucleus in control of gonadotropin secretion (1953). Later studies showed that hypothalamic lesions would increase prolactin secretion and suppress growth hormone release (1960-64).

5 Testing of the neurohumoral concept of activation of pituitary secretion which revealed that vasopressin was an important corticotropin-rel easing factor. Furthermore, lesions destroying the supraopticohypophysial tract led to a deficiency in ACTH secretion. Development of the concept that vasopressin delivered to the pituitary gland by the hypophyseal portal vessels was a controller of ACTH secretion (1954).

6 Obtained conclusive evidence that there was another corticotropin-releasing factor other than vasopressin which was localized to the median eminence region, whereas vasopressin was the major CRF in the neural lobe of the pituitary gl and (1959).

7 Demonstration of the fact that cortical steroids acted back to suppress vasopressin secretion (1958); and that there were similar negative feedback effects of pituitary target gland hormones mediated at both the hypothalamic and pituitary level (1963-75).

8 Discovery of LHRH (1960).

9 First purification of growth hormone-releasing factor. Purification of CRF, LHRH (1962-64).

10 Demonstration of a prolactin-inhibiting factor in in vivo studies (1963).

11 Discovery of the FSH-releasing factor (1963) which could be separated from the LH-releasing hormone by gel filtration on Sephadex (1964) followed by CMC chromatography (1966).

12 Discovery of the growth hormone release inhibiting factor (1968), now called somatostatin, its purification and separation from growth hormone releasing factor and its localization to the $\mathrm{VMH}$ arcuate region before the structure was determined (1968-72).

13 Localization of $\mathrm{LHRH}$, growth hormone rel easing factor and prolactin inhibiting factor to regions of the hypothalamus subsequently shown to contain these by radioimmunoassay (1965-70).

14 Discovery of the short-loop negative feedback of GH (1966-67).

15 Evidence that puberty is caused by resetting of the hypothalamic gonadostat (1965).

16 Study of mechanism of action of LHRH at the pituitary gland and the fact that stalk-median eminence extracts would increase cyclic AMP and adenylate cyclase activity in the pituitary (1969-72).

17 Discovery of the role of $\mathrm{PGE}_{2}$ in control of release of FSH and LH by stimulation of LHRH release (1973).

18 Discovery of the activity of LHRH to induce mating behavior (1973).

19 Separation of the hypothalamic areas controlling the release of LHRH from those controlling FSH-RF by stimulation and lesion experiments (1973).

20 Discovery of glucagon-releasing factor and insulin-release inhibiting factor (Galanin) and their purification (1977-85).

21 Characterization of the actions of a variety of brain peptides on hypothalamic pituitary function with proof that some of these had physiological significance in controlling either the release of releasing hormones, or the response of the pituitary to them (1980-present).

22 Demonstration of ultrashort-loop feedback of somatostatin (1981), GRF and LHRH (1985).

23 Other studies by radioimmunoassay and bioassay demonstrating the separation of FSH-RF from LHRH on gel filtration and further evidence of acute dissociations in $\mathrm{FSH}$ and $\mathrm{LH}$ release by various transmitters and the fact that LHRH analogs and the GAP peptide 1-13 had selective FSH-releasing activity. Work is in progress to isolate the FSH-rel easing factor (1983-present).

24 Further evidence that catecholamines act directly on the pituitary by $\beta$ receptors to control gonadotropin secretion (1983).

25 Characterization of the actions of cytokines at hypothalamic and pituitary levels on the secretion of the various anterior pituitary hormones (1985-present). 
Table 1 Continued

26 Delineation of the central nervous system control of the rel ease of ANP (1989-present). These studies are ongoing and indicate that volume expansion activates baroreceptor input into the AV $3 \mathrm{~V}$ region which in turn activates ANP neurons which cause the rel ease of oxytocin from the neurohypophysis; oxytocin then circulates to the right atrium and induces the release of ANP which mediates natriuresis.

27 Discovery of the role of nitric oxide to stimulate the rel ease of LHRH, CRF, GHRH, SRIF, PRL-releasing factors, but not FSH-RF (1991-present).

28 Discovery of the mechanism by which ethanol, cytokines and delta-9-tetrahydrocannabinol suppress LHRH release by blocking the conversion of arachidonic to $\mathrm{PGE}_{2}$ by a direct suppression of activation of cyclooxygenase by nitric oxide (1994).

29 Discovery of the role of nitric oxide to activate soluble guanylate cyclase to provide substrate for conversion to PGE ${ }_{2}$ (1994).

30 Discovery of the mechanism of action of dopamine to inhibit PRL release by activation of nitric oxide release which then el evates cyclic GMP in the lactotrophs resulting in suppression of PRL release (1994).

31 Discovery of oxytocin receptors in the heart and evidence that oxytocin activates these receptors to produce a negative ino- and chronotropic effect by in vitro experiments indicating that oxytocin is a powerful hormone which decreases effective circulating blood volume by release of ANP that reduces cardiac output, dilates vessels and then eventually produces natriuresis to return blood volume to normal (1997).

32 Demonstration of the action of leptin to stimulate FSH and LH from the pituitary via nitric oxide with a potency not significantly less than that of LHRH itself. Leptin also stimulates LHRH release from the hypothalamus in vitro via nitric oxide. Intraventricular injection of leptin in ovariectomized estrogen-primed animals can stimulate LH release and inhibit FSH release (1997).

33 Determination of the nature of FSH-RF (1997). 